\title{
Management System for Key Knowledge Workers - Initial Assumptions
}

\author{
Mieczysław MORAWSKI \\ Warsaw University of Technology, Warsaw, Poland \\ mieczyslaw.morawski2017@gmail.com
}

\begin{abstract}
The analysis of the subject literature provides very few ideas for the management of knowledge workers. There is an extensive research gap in the study of methods participation and involvement key knowledge workers in different management processes. There are no proposals for management systems dedicated to the key knowledge workers. The article has a theoretical character referring to previously conducted by the author of the research. The aim of this paper is developed a model of key knowledge workers' management within intelligent organization. These are initial assumptions for the model that need to be developed in subsequent studies. The research was based on survey studies. The survey questions were addressed to entrepreneurs and managers. The study sample consisted of several SME businesses operating in the sector of creative industries in Poland. According to the author of the study more and more mature models of knowledge workers' management are needed. The sector of creative industries is the most developed high-tech sector in Poland with the decisive role of knowledge workers.
\end{abstract}

Keywords: Knowledge Worker, Key Knowledge Worker, Management System.

\section{$1 \quad$ Introduction}

In the times of a breakthrough we expect from science and scientists to provide responses to many questions and uncertainties. New phenomena occurring in an organization and management require a different perception. New theories and approaches are crystallized. The new categories, for example: economy based on knowledge, knowledge management, knowledge workers (or key knowledge workers) reflect changes occurring in an enterprise which leading resource is represented by people, therefore interpersonal factors and their impact on effective organizational resources implementation constitute the basic research dimension.

Knowledge-Based Economy (KBE) is the economy that is replacing the industrial economy. The "New Economy" is a stepping-stone towards it. The ways of doing business and managing are changing very fast. We can watch paradigm shifts and emerging new paradigms right now. The crucial research problem of the management science is the methods of KWs management within modern economy. 
It has become the basic principle in human resources management to pay employees for thinking and not for just time spent on company premises. Creating a model of management knowledge workers, we need to solve many problems. It's necessary to answer such questions, for example:

1. What is the difference between a knowledge worker and a factory worker?

2. What is the difference between managing by forcing and management by encouraging?

3. What is the importance of factors related to human capital in achieving high efficiency of the entire organization functioning?

4. How to show appreciation to KWs?

5. How to encourage transfer and sharing of knowledge?

6. Which characteristics are desirable in the environment of KWs to encourage their creative thinking and operating?

7. How enforce and evaluate the effects of tasks performed when managers are not the experts and don't know of all the consequences of the adopted and approved solutions?

8. How do we should encourage him to extra effort and sacrifices emotionally unrelated to the organization?

9. From what elements: methods, processes, tools should be composed of human capital management system?

In particular: how to develop work environment which functions as the creative thinking and action incentive for the discussed KWs?

I identified issues, processes and challenges primarily focused on the problem of managing knowledge workers in knowledge-based organizations (talent management, motivation for knowledge sharing, the development of competences, work in creative teams and others). These modern plants are often called intelligent organizations (IO). The majority of IO's workers are knowledge workers. Highly gifted people represent the core competencies of the IO $[11,10]$.

I categorized knowledge workers by distinguishing: promising talents, mature specialists, managers of knowledge management processes and also key workers.

The literature studies I have conducted, focused on the research covering the flow of knowledge in enterprises and my own observations and analyses, as well as numerous interviews with managers allowed me to conclude that the most extensive problem and challenge of its effective stimulation, support and application is the develop of key knowledge workers management system.

Managing key KWs is a difficult challenge. Solutions to empower the best employees are needed. Specific management without management: high level of autonomy, various work hours, motivation referring to the content of work, personal responsibility, opportunities for continuous development and learning. Key KWs must be treated as unique people.

Due to the unique contribution that creates added value in the form of - for example - products or technologies, key KWs have the right to expect special working conditions. Therefore, IO units have to create the adequate working environment for 
the specialists. The comfort's zone for them guarantee that key KWs become aware investors of their own intellectual capital.

The article has a theoretical and empirical character referring to previously conducted by the author of the research. The aim of the study is to indicate the elements of the management system of key knowledge workers based on a set of determined features of this group of employees.

The determined features of a key knowledge worker have become the starting point to propose basic elements of the management system of these employees.

\section{Knowledge Workers and Key Knowledge Workers}

In the 1950s Peter Drucker may have been the first to describe „knowledge workers” and „knowledge work” [5]. Knowledge workers are workers whose main capital is knowledge. Examples include software engineers, doctors, physicians, pharmacists, architects, scientists, lawyers and academics, whose job is to "think for a living" [3]. Davenport defines a knowledge worker as an employee who has a high level of expertise, training or experience and the main purpose of his work involves the creation, distribution and application of knowledge. While Drucker specifying the products of working knowledge worker says that the result of their work are not physical objects, but knowledge and ideas [2]. In turn, Davis and Parker argue that the work based on knowledge is a human mental work performed in order to generate useful information. During this work knowledge workers find information, using the knowledge involved mental models, using concentration and attention [4]. Perhaps the most succinct definition of this category of workers is offered by Abbasi who states that knowledge workers are the ones who add value to an organization based on what they actually know [1]. Davenport sees knowledge workers as people with high degrees of expertise, education, or experience. Knowledge workers think for a living [3]. Mladkova states that knowledge workers represent the special group of highly qualified employees. The specifics of their work and management reflect the intangibility of their major tool and resource, i.e. knowledge-[6].

The author's analysis of subject literature allows concluding that the term "knowledge worker" covers the following characteristic [8]:

1. High expectations regarding the autonomy and empowerment.

2. High competencies and expertise supported by unique knowledge and experience.

3. Versatile skills of creative thinking.

4. Interpersonal, leadership oriented skills.

5. Applying knowledge in its various processes.

6. Involvement in creating new knowledge constituting the basis for innovative processes and solutions.

7. Presenting "tacit" knowledge which offers opportunities for creating added value in an organization.

8. Intellectual, essential and emotional commitment. 
9. Waiting for organizational comfort, which provides him/her with extensive independence and opportunities for professional skills advancement.

10. Striving to create an organizational culture based on a high level of professionalism - knowledge, competence, continuous learning and other.

11. Creative thinking is the major part of their activity

Currently, knowledge workers are considered as the most important assets of an organization. The created new business models are people who are very knowledgeable, well that used allows optimal use of the remaining resources of the company, becoming its main assets.

Table 1. The most important differences between management by forcing (classic approach) and management by encouraging (an approach based on human capital) $[3,6,8,11]$.

\begin{tabular}{|c|c|c|}
\hline Features & Management by forcing & $\begin{array}{l}\text { Management by } \\
\text { encouraging }\end{array}$ \\
\hline Type of employee & Factory worker & Knowledge worker \\
\hline Type of work & $\begin{array}{l}\text { Mainly physical work: } \\
\text { fitting, installation, } \\
\text { connection }\end{array}$ & $\begin{array}{l}\text { Mental work: analysing, } \\
\text { comparing, consulting, } \\
\text { prediction, forecasting, } \\
\text { synthesizing, problem } \\
\text { solving }\end{array}$ \\
\hline Significant effect & Goods; single invention & Ideas;Continual innovation \\
\hline Key needs of staff & $\begin{array}{l}\text { Visible success criteria in } \\
\text { career, employment contract } \\
\text { for an indefinite period }\end{array}$ & $\begin{array}{l}\text { Long-life learning, } \\
\text { autonomy, comfortable } \\
\text { working conditions, } \\
\text { attractive tasks and } \\
\text { projects }\end{array}$ \\
\hline Motivation & $\begin{array}{l}\text { Competition for individual } \\
\text { prizes and bonuses for } \\
\text { availability }\end{array}$ & $\begin{array}{l}\text { Cooperation in teams: } \\
\text { bonuses for contributions } \\
\text { and commitment }\end{array}$ \\
\hline Leadership style & Manager-superior & Manager-partner \\
\hline Management system & Based on hierarchy & $\begin{array}{l}\text { Based on partnership in a } \\
\text { social network }\end{array}$ \\
\hline $\begin{array}{l}\text { Internal organizational } \\
\text { architecture }\end{array}$ & $\begin{array}{l}\text { Functional areas, e.g.: } \\
\text { production, } \quad \text { logistics, } \\
\text { marketing, } R \& D \text {, finance }\end{array}$ & $\begin{array}{lr}\text { Processes, e.g.: } & \text { customer } \\
\text { service, flow } & \text { of } \\
\text { information, } & \text { sharing } \\
\text { knowledge, } & \text { staff } \\
\text { development, cooperation } & \text { with suppliers }\end{array}$ \\
\hline Work environment & $\begin{array}{l}\text { Performing } \quad \text { tasks in } \\
\text { functional } \\
\text { limits }\end{array}$ & $\begin{array}{l}\text { Performing tasks in small } \\
\text { often virtual project teams }\end{array}$ \\
\hline Essential processes & Production processes & $\begin{array}{l}\text { Processes of organizational } \\
\text { learning and knowledge } \\
\text { management }\end{array}$ \\
\hline
\end{tabular}


Productive management of knowledge and others invisible resources requires special approach towards individuals who have the highest level of own intellectual capital. Without them an ongoing inflow of new knowledge, original ideas and innovations would not be possible. Owing to their high qualifications and experience they present knowledge which is unavailable for others.

One of the crucial challenges in Human Capital Management - conceptual and practical - is to encourage key employees to share their knowledge (expertise and experience, skills, good practices, ideas) with co-workers inside the company (see Tab.1).

Key employees are a top class specialist constructing the intellectual and substantive elite. They constitute the group of knowledge workers who have decisive influence on the value of core corporation competencies. They provide unique skills, extensive professional contacts, deep and broad experience. Knowledge which they have acquired is not only advanced, but also an innovative and unique one and therefore it is always of highly individual nature (so-called: tacit knowledge). They include specialist, for example: high-class engineers, technologists, programmers, economists and experienced managers.

According to author's findings from recent years, following recommendations are respectively provided in order to improve job factors and increase the occurrence of attitudinal and behavioral variables which may result better management of key KWs:

- Authorization and personal responsibility for employees on some tasks;

- To provide individual appraisals and feedback of personal performance;

- To use flexible work schedule;

- To allow teleworking for some tasks;

- To allocate more budget and time (and more attention, indeed) to research, functional development, collaboration and interaction with scientific societies;

- To implement plans such as job turnover, job enrichment and empowerment of workers;

- To explain mission and vision of organization to workers and to involve them in decision making process.

\section{Empirical Research and Discussion}

The first research was conducted in the years 2012-2103 and was based on a sample consisting of 50 enterprises. The target group covered enterprises seated in western and south-western Poland. Two research tools were applied in the underlying analyses, i.e.: survey questionnaire addressed to entrepreneurs and managers and an interview questionnaire addressed to key employees. The survey questionnaire applied in the study included 18 questions divided into 3 thematic blocks: company management, key employee profile and key workers involved in the knowledge sharing process. The questions were mostly of closed type ones. An interview consisted of open questions and its purpose was to provoke key employees for presenting deeper reflections and their own, personal opinions [7]. The second research in the period June-July 2015, conducted surveys in 11 selected, private 
businesses located in south-western Poland. All questionnaires were filled in by the businesses' owners. The research was based on the questionnaire prepared by the Author, made up of 10 substantives, closed questions with a choice of answers [8].

The conducted empirical studies, in-depth subject literature review and the author's own original considerations and observations resulted in collecting important findings:

- detailed identification of a knowledge worker's profile by analysing the subject literature interpretations of different authors and own experiences resulting from in-depth literature studies, previously conducted empirical research, implementation projects for business practice;

- developing a competency profile of a key employee, who can help and support determining the place, role and effects of professional activity of the discussed employee group;

- determining the structure of duties remaining the responsibility of key employees;

- systematizing the factors influencing the intensification of knowledge sharing processes;

- developing the catalogue of challenges for managing key knowledge workers, specifying potential/actual benefits and risks.

One of the significant results of these two studies was to determine a set of characteristic features of a key knowledge worker defining his/her competences, organizational roles, motivations, etc. (see Tab.2).

Table 2. Features of key employees.

\begin{tabular}{ll}
\hline \multicolumn{1}{c}{ Features / categories } & \multicolumn{1}{c}{ Key employee } \\
\hline Substantive competencies & $\begin{array}{l}\text { Unique, top quality knowledge based on } \\
\text { many years of experience and master skills }\end{array}$ \\
Other valuable competencies & $\begin{array}{l}\text { Leadership skills, extensive contacts in the } \\
\text { sector (with suppliers, clients, scientists, } \\
\text { investors), innovative approach, mentoring } \\
\text { skills }\end{array}$ \\
& Unique \\
Intellectual potential & $\begin{array}{l}\text { Practically impossible, requires the } \\
\text { introduction of long-lasting programmes } \\
\text { fubstitution for a leaving employee }\end{array}$ \\
& successors
\end{tabular}


Organizational roles: performed in the same time or different time

Incentives

Accomplished career level

Fundamental work results
- $\quad$ top level manager

- management representative

- $\quad$ innovator and the author of patents

- coordinator and leader of many projects

- mentor

- internal trainer

- $\quad$ supervisor of newly admitted employees

- $\quad$ individually agreed salary

- $\quad$ extensive financial means for trainings

- contracts for participation in company profits

- $\quad$ comfortable work conditions adjusted to individual preferences

- $\quad$ flexible working hours

- autonomy on the workplace

- $\quad$ professional comprehensive qualifications

- $\quad$ authority of knowledge

- recognition and fame outside the company

- $\quad$ initiating changes based on creative thinking

- $\quad$ implementation of systemic management concepts

- $\quad$ establishment of new products generations

The conclusions resulting from the carried-out research allowed formulating the proposals for basic guidelines related to the construction of a comprehensive knowledge workers' management system, which may become useful for enterprises and their managers. These guidelines relate to e.g. the needs for identifying the core values of an enterprise, defining its mission, vision and strategic goals, developing the key competences of an intelligent organization, attracting and identifying key knowledge employees, developing the personnel strategy for knowledge workers. The listed guidelines for the development of a comprehensive key employee management system indicate the directions of crucial strategic choices. In the system of a specific enterprise/organization - while maintaining the above-mentioned fundamental principles - the time priorities of particularly valuable (important) issues, areas, challenges and processes for the company should be defined.

The key KWs expect organizational comfort which provide him/her with extensive independence and opportunities for professional skills advancement. They also value 
organizational culture in which competencies and knowledge are respected and have impact on the entire company personnel attitudes and behavior.

\section{The Comprehensive Key Employees Management System - Author's Assumptions}

The results of the previous study [7,9] were used to develop a model of intelligent organization used in CI companies (see in Fig. 1.) In the light of the research conducted by the author it seems appropriate to recommend the following factors for providing effective business model in CI [9]:

- Culture of Knowledge Sharing (CKS);

- Knowledge Workers Management (KWM);

- Team Organizational Forms (TOF);

- Advanced Production Technology \& Communication (APT\&C).

The business model in CI is an original author's version of the concept of the intelligent organization which has the following attributes:

- organization gathers knowledge potential,

- constructing strategic advantage based on unique competencies,

- dynamic continuous changes,

- moving from functions to processes,

- abandoning hierarchy for relations,

- making team work common,

- capturing and keeping workers with high intellectual potential,

- open communication supported by IT, ICT.

This model will be permanently expanded with the next essential elements in the intelligent organization. It should to be suspected particularly intensive conception research in the range of knowledge workers management and organization solutions.

Particular solutions referring to key employees can follow the suggestions presented below [8]:

1. Career based on work positions rotation, changing organizational roles, performing different, changing in time and scope functions for an organization, taking part in different projects.

2. Promotion depending on sharing one's own experiences with others: playing the role of an internal coach, mentor, trainings, seminars and conferences organizer.

3. Social competencies development by organizing knowledge sharing places: workshops for particular departments, meetings with new employees, inviting key and less experienced employees to work together in the same team.

4. Organizational culture creation based on the sense of creating cooperating community underlying collective responsibility principles: organizing events 
for particular occasions gatherings of all company employees, joint celebrations of both the company and individual employees success, motivation oriented business trips, meetings with families, etc.

5. Company environment monitoring by means of formal relations (personal consultancy agencies, universities, research and development institutes) and informal ones (distinctive scientists, patent authors, inventors, professional experts) in order to attract the best candidates from the environment.

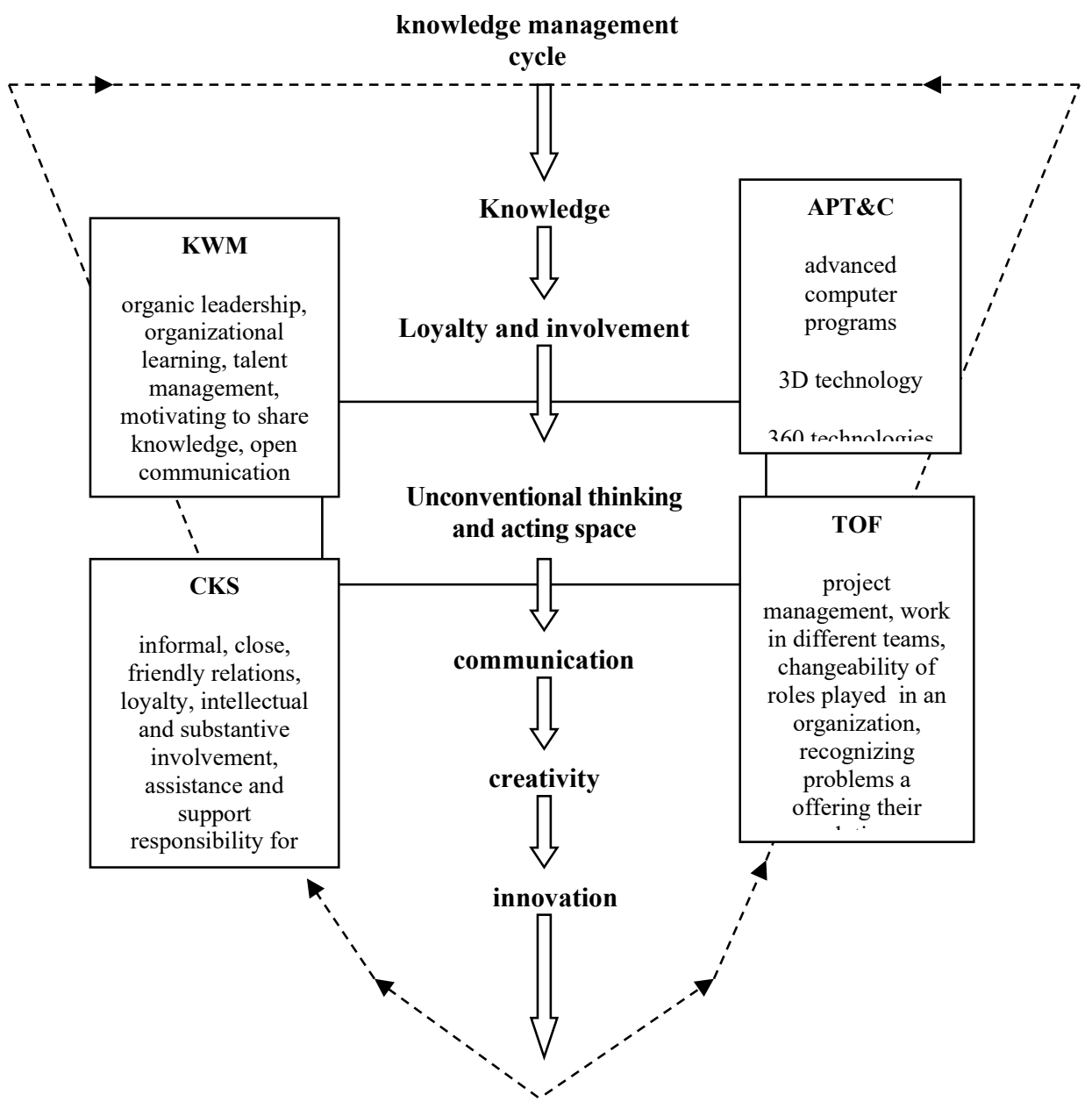

Fig.1. Model of intelligent organization used in Creative Industries.

\section{Conclusions}

Without key employees' satisfaction it is hard to establish an effective management system in an enterprise. Thus, however is not an easy problem to solve. Similar, or 
even higher salary may be offered to them in another company. In the author's opinion it is indispensable to create the concept of an adequate work environment for this particular group of employees. In the discussed model-oriented perspective financial incentives are key employees expects organizational comfort which provides him/her with extensive independence and opportunities for professional skills advancement. A key employee also values organizational culture in which competencies and knowledge are respected.

When the intellect becomes a critical production factor, the successful enterprises differ from the less effective ones predominantly in their approach towards employees Managing knowledge workers in an enterprise within the CI sector should not take the form of a closed project with ultimately outlined goals. The effects to be expected are continuous and essentially timeless, such as the development of good practices or the intensification of learning processes.

It is necessary to continue the research in the area of knowledge workers' management in creative industries. The following research areas seem particularly interesting:

- Comfort and relaxation as the factors stimulating creative thinking vs. rigid formal and legal requirements: working time, scope of duties;

- Difficulties in reconciling diverse preferences of the successive generations of workers, primarily between the youngest " $Z$ " generation representatives and the other ones;

- Encouragement for knowledge sharing between the key workers and the newly employed ones.

\section{References}

1. Abbasi, S. M., Belhadjali, M., Hollman, K.W.: Managing Knowledge Workers for Sustaining Competitive Advantage. Competition Forum 7(2), 367-370 (2009).

2. Cooper, D.: Knowledge Workers. Canadian Business 79(20), (2006).

3. Davenport, T. H.: Thinking For A Living: How to Get Better Performance and Results From Knowledge Workers. Harvard Business School Press, Boston (2005).

4. Davis, G. B., Parker C. A.: The doctoral dissertation. Systematic approach. Barron's Educational Series, New York (1997).

5. Drucker, P. F.: The Landmarks of Tomorrow. Harper and Row, New York (1959).

6. Mladkova, L.: Knowledge Worker from the Perspective of Their Manager. In: Janiunaite B., Petraite M. (eds.). Proceedings of the 14th European Conference on Knowledge Management, pp. 446. Kaunas University of Technology, Kaunas, Lithuania (2013).

7. Morawski, M.: Polish National Knowledge Management Styles. Studies in selected companies representing creative industries. In: Vivas C., Sequeira P. (eds.). Proceedings of the $15^{\text {th }}$ European Conference on Knowledge Management, pp.708-715. Polytechnic Instytute of Santarem, Santarem (2014).

8. Morawski, M.: Business model used in companies representing creative industries. In: Sindakis, S., Theodorou P. (eds.). Global Opportunities for Entrepreneurial Growth: Coopetition and Knowledge Dynamics within and across Firms, pp. 55-74, Emerald Publishing Limited, Bingley, United Kingdom (2018). 
9. Morawski, M., Piepiora, Z., Rogala, P.: Model of enterprise management in the creative industries on the basis of empirical research. Review of Business Research 17(1), 61-66 (2017), DOI: 10.18374/RBR-17-1.7.

10. Nonaka, I., Takeuchi, H.: The Knowledge Creating Company. Oxford University Press, Oxford (1995).

11. Thannhuber, M. J.: The intelligent enterprise: theoretical concepts and practical implications. Physica-Verlag, A Springer Company, New York (2005). 